\title{
El principio de servicio objetivo a los intereses generales en la Constitución y su traducción legislativa
}

\author{
Daniel Berzosa López \\ Doctor Europeo de Investigación de Derecho Constitucional por la Universidad de Bolonia \\ Profesor de Derecho Constitucional y Derecho Público de la Empresa de CUNEF \\ (Universidad Complutense de Madrid) \\ daniel.berzosa@chmabogados.es
}

\begin{abstract}
Resumen
La Constitución aborda de forma expresa el tema del servicio objetivo de las administraciones públicas a los intereses generales en su artículo 103.1. Este mandato constitucional es el fundamento primero de la actuación de las administraciones públicas, de modo que otros principios podrán agregarse; pero este, en ningún caso, podrá obviarse y menos anularse. El legislador constituyente determinó, por tanto, que el interés general servido objetivamente fuera un principio constitucionalizado. La consecuencia jurídica evidente es que las administraciones públicas, cuya actuación está sometida a la vinculación positiva a la norma, disfrutan de un grado de autonomía de la voluntad que no es equivalente en este aspecto a la de un particular. Así, en su actuación entre ellas y con los particulares, deberán ajustarse a la búsqueda y prosecución del interés general que corresponda de forma objetiva o neutral, de conformidad con la voluntad general.
\end{abstract}

Palabras clave

Constitución, administraciones públicas, servicio objetivo, interés general, ley.

\section{The objective service to general interest in the Constitution and its legal translation}

\begin{abstract}
The Constitution explicitly addresses the issue of the objective service of civil administrations to general interests in Article 103.1. This constitutional mandate is the first foundation of the action of the civil administrations, so that other principles may be added, but this, in any case, may be dispensed unless canceled. The framers of the Constitution decided, therefore, that the public interest objectively served was a constitutionalized principle. The obvious legal consequence is that civil administrations, whose performance is positively subjected to the norm, have a degree of autonomy that is not equivalent in this respect to a particular. Thus, in their relations among themselves and with the public, shall comply with the search and pursuit of the public interest objectively or neutraly appropriate, in accordance with the general will.
\end{abstract}

Key words

Constitution, public administration, public service, public interest, law. 


\section{INTRODUCCIÓN}

El abigarrado cúmulo de circunstancias negativas que, en el presente, gravitan sobre nuestra democracia constitucional, determina también que recobre actualidad la cuestión de la efectiva realización del servicio objetivo a los intereses generales que deben prestar las administraciones públicas, de acuerdo con la Constitución.

Como todos los temas de actualidad, no resulta por ello más claro, sino que, al contrario, es un tema cuya delimitación puede resultar más confusa en el presente; porque, por parte de la especulación teórica, intencionadamente o no, en ocasiones, se ha complicado la cuestión al intentar una simplificación que no es posible y, en otras, al intentar evitar el error de simplificar de forma arbitraria lo complejo, el resultado ha sido complicar de forma innecesaria lo simple.

Para comprender adecuadamente la aspiración de la objetividad de la actuación de las administraciones públicas al servicio del interés general, debe enmarcarse en la propia concepción del "estado liberal de derecho" y de su transformación en esa construcción que los constitucionalistas llamamos "estado social de derecho" y que, aun reconocido en los textos constitucionales, no ha tenido el desarrollo debido.

Con la brillantez que lo caracteriza, el profesor De Vega' ha resumido el núcleo de este inevitable punto de partida para entender lo que se espera — ciertamente como derivada del núcleo del sistema constitucional- de unas administraciones públicas propias del Estado Social, en el que estamos insertos. Al partir la concepción liberal de la distinción entre sociedad y estado, resulta imprescindible el establecimiento de un doble estatuto jurídico. Uno que regule el estado y otro que regule la sociedad. Por supuesto, el estatuto del estado es la constitución, que es distinto del estatuto de la sociedad (caso de los códigos civiles y mercantiles). Así, esta comprensión y su genial plasmación por Napoleón en las dos grandes instituciones que dejó a Francia (el régimen jurídico de la administración del estado y, claro es, el código civil) es lo que le han granjeado la verdadera posteridad.

Naturalmente, para que la administración pública y su actuación respondan a la idea de constitución, el entero conjunto tiene que estar sometido a aquella norma en primer lugar. El constitucionalismo, entendido en su forma contemporánea (Sartori ${ }^{2}$ ), supone dar respuesta a los sueños de un Juan de Salisbury ${ }^{3}$ o un Marsilio de Padua ${ }^{4}$, por cuanto pone fin al siempre caprichoso gobierno de los hombres con la introducción de una norma que obliga, de verdad y por igual, a gobernantes y

$1 \quad$ Cfr. De Vega, P.: “El problema de los derechos fundamentales en el Estado Social”, en Anuario Jurídico de La Rioja. Diputación General de La Rioja-Universidad de La Rioja. Logroño, 1997; pp. 365 ss.

2 Sartori, G.: Elementos de teoría política, Alianza Editorial, Madrid, 1999; p. 20: "Históricamente, el término constitución era un vocablo "vacante" del que se apropió el constitucionalismo en el siglo XVIII para dar la idea de un gobierno de las leyes (no de los hombres) y limitado por las leyes".

445 Juan de Salisbury, Policraticus (1159), Madrid, 1984; libro IV, cap. 1, pp. 306-307. 
gobernados. En el mundo clásico y medieval, la obediencia de los individuos a la ley se encontraba perfectamente garantizada; pero no la de los gobernantes. En el estado constitucional, la constitución se aplica a todos los ciudadanos sin distinción, con independencia de la posición (activa o pasiva, interna o externa) que ocupen respecto del poder político5. El valor y fuerza de la constitución no se entenderán de forma correcta si solo se la concibe como un conjunto de principios; es una norma esencial e indiscutiblemente jurídica. Lo que quiere decir que contiene auténticos mandatos obligatorios y vinculantes, cuya infracción lleva aparejada alguna clase de sanción ${ }^{6}$.

De esto se sigue, según Kelsen7, que la función ejecutiva en el estado constitucional está sometida necesariamente a la idea de legalidad y ello, a su vez, impone la introducción del sistema burocrático o de administración pública racional (Weber ${ }^{8}$ ) en la organización del estado. El principio de legalidad a que está sometida de ese modo la función ejecutiva o de gobierno y, con más razón, las administraciones públicas, debe excluir cualquier influencia partidista sobre la aplicación de las leyes por las autoridades administrativas (aún más, por supuesto, en el caso de los tribunales propios de este orden jurisdiccional).

Una precisión se impone. La referencia kelseniana a la "función ejecutiva" tiene pleno sentido en este marco y se integra de forma lógica en el objeto del artículo si se tiene presente la comprensión de Max Weber sobre el campo de acción de la administración pública, que, sin duda, comparte el profesor austríaco-estadounidense: “En el sentido más amplio, el círculo de la administración 'pública' encierra tres clases de tareas, a saber: creación del derecho, aplicación del mismo y lo que queda de la actividad de los institutos públicos después de separar aquellas dos esferas: lo que llamaremos 'gobierno"'?.

Volvemos a lo que decíamos en las primeras líneas de esta introducción. Porque, con esta modesta contribución, no se trata precisamente de simplificar lo complejo, ni de complicar de manera caprichosa lo simple (y menos en una obra colectiva que cuenta con el concurso de notables especialistas del derecho administrativo), nues-

5 Cfr. De Vega, P.: "Supuestos políticos y criterios jurídicos en la defensa de la Constitución: algunas peculiaridades del ordenamiento constitucional español”, en Revista de Política Comparada, n. ${ }^{\circ}$ 10-11 (1984); pp. 403-404.

6 Vid., por todos, García de Enterría, E.: “La Constitución como norma jurídica”, en A. Predieri y E. García de Enterría (dirs.) y otros, La Constitución española de 1978. Estudio sistemático, Madrid, 1981; pp. 97158. De Otto, I.: Derecho Constitucional. Sistema de fuentes, Madrid, 1987; pp. 13-14. Pérez Royo, J.: Las fuentes del Derecho, Madrid, 1988; pp. 33 ss.; Curso de Derecho Constitucional, Madrid, 1996, pp. 152 ss y p. 172.

7 Cfr. estas ideas en Kelsen, H.: Esencia y valor de la democracia, Labor, Barcelona, 1977; pp. 99 a 109.

8 Cfr. Weber, M.: Economía y sociedad, Fondo de Cultura Económica, México DF, 1944; pp. 208, 771 y 775 .

9 Ibidem, p. 500. Precisa el editor de la obra en nota de la misma página que, "en alemán, tenemos las expresiones Rechtsschöpfung, creación del derecho, su establecimiento; Rechtsfindung, encontrar el derecho, su aplicación; Regierung, regimiento, gobierno". 
tra exposición se limitará a realizar unas breves consideraciones sobre los aspectos esenciales del tema, desde la perspectiva de la teoría constitucional. Partimos $-\mathrm{y}$ este es el dato que nos servirá de punto inicial de referencia- de que el servicio objetivo de las administraciones públicas a los intereses generales ha pasado a integrar la normativa constitucional, con las consecuencias que ello implica.

\section{ADVERTENCIA METODOLÓGICA}

Algunas líneas deben dedicarse a la cuestión del método. Y no solo para lograr, dentro de lo posible, una cierta claridad, sino para intentar conseguir algún resultado útil. A nadie se oculta que la superposición de la palabra "objetividad” y la expresión "intereses generales" cobra un significado diferente, según los contextos y el uso que se realicen de ellas, si la cuestión se aborda desde una perspectiva principalmente ideológica o desde una literal.

En todo caso, en esta materia y pese a alguna opinión autorizada en sentido contrario $\left(\right.$ Nieto $\left.^{10}\right)$, no se puede renunciar a contrastar los resultados con la realidad social, ni se puede dejar de tratar de integrar el derecho en la realidad social; pues el derecho es una ciencia por definición social y ello, aunque se deba correr el riesgo, ciertamente cercano, de confundir uno y otro ámbito y en lugar de caer del lado de las respuestas o delimitaciones del problema, se caiga en el de la vaguedad. Porque el derecho no es algo puro, no es solo idea, algo meramente mental, sino que adquiere su valor y sentido, se hace en contacto con la sociedad donde está vigente y se desenvuelve. Es un riesgo que hay que correr. Lo importante será entonces escoger el punto de partida menos distorsionado.

En este sentido, apelamos al gran liberal inglés John Stuart Mill, quien, al escribir en su System of Logic que "el significado de una palabra bien puede ser aquel que conlleva una común aceptación o aquel que el escritor o el orador intenta darle”, prefigura una distinción que los modernos filósofos del lenguaje retomarán en forma de definiciones estipulativas y definiciones lexicográficas. Una definición ideológica o estipulativa es aquella en la que el autor asigna un contenido y un significado deliberado y concreto a lo que intenta definir. Una definición literal o lexicográfica se refiere al significado general y comúnmente aceptado de las palabras o de los conceptos (Robinson). Siguiendo y parafraseando a mi maestro, el profesor De Vega, pese al riesgo de incurrir en una generalización excesiva, parece más conveniente recurrir a la comprensión de los conceptos indicados desde su consideración lexicográfica, y no desde la ideología"1.

10 Cfr. Nieto, A.: “La administración sirve con objetividad los intereses generales”, en Estudios sobre la Constitución española (homenaje al profesor Eduardo García de Enterría), III. Civitas. Madrid, 1991; pp. 2190 ss.

$46 \quad 11 \quad$ De Vega, P.: Legitimidad y representación en la crisis 
Ni que decir tiene que, cuando la palabra objetividad y la expresión intereses generales se emplean de forma lexicográfica equivale a decir, sensu contrario, que hasta un cierto punto carece de fundamento hablar de clases de interés general o de distintos intereses generales. Cabe perfectamente imaginar la posibilidad de que coexistan intereses particulares en una sociedad con un índice de atención muy elevado al interés general, no obstante, por parte de del estado y sus administraciones públicas.

Resulta llamativo el hecho de que las repercusiones negativas en la apreciación del interés general en el Estado Social, como consecuencia de la crisis de este modelo de estado en las sociedades industriales avanzadas (denunciado ya en el año 1973 por James O'Connor en su obra clásica The fiscal crisis of the State), se hayan pretendido compensar con la apelación a procesos de legitimación concretos de ciertas instituciones o ámbitos de actuación administrativa, y con la descomposición y fragmentación de la noción de acción política clásica (politics) en múltiples políticas públicas (policy), para cada una de las cuales se intenta procurar su propia estructura de interés general, desde los supuestos elementos participativos y los falaces componentes democráticos del llamado policy process, que, por mucho que se adorne, no deja de ser el conjunto de técnicas y estrategias que definen la gestión de las políticas públicas.

Hablar, en estas circunstancias, de distintas clases de interés general y fragmentar la noción de interés general, equivale a errar en la lógica del razonamiento, y a eludir la problemática en torno a la idea de interés general en la democracia constitucional, que es precisamente lo que se trata de plantear y discutir. Y este interés general tiene que estar conectado a la fuerza, esto es, por necesidad con la noción de voluntad general. Sucede, no obstante, que en el plano histórico real la construcción de la voluntad general se ha hecho siempre más problemática y compleja que su fundamentación teórica.

El mismo Rousseau, el gran defensor de la democracia directa y consciente de los problemas que suponía la obligada introducción de los esquemas de la democracia representativa, indica en El contrato social (libro III, capítulo XV) que la contraposición entre democracia directa y democracia indirecta, entre democracia de la identidad y democracia representativa o constitucional, es inexorable y antagónica, por lo que no sería posible alcanzar un interés general auténtico mediante la democracia indirecta (que es la que, por otro lado, se ha generalizado en todos los estados democráticos). Esta postura se vería confirmada por la comprensión del interés general que ofrece Carl J. Friedrich en El interés público ${ }^{12}$.

De modo que Rousseau señalaría que, en el estado constitucional (tanto "liberal” como "social”), la especialización derivada de la división del trabajo y que se proyecta en los distintos brazos del poder del estado, con sus propios intereses, hacen que el

12 Cfr. Friedrich, C. J.: El interés público, Roble, México DF, 1967; p. 201. 
interés general y el servicio objetivo a este no puedan ser en verdad expresión de la voluntad general, sino que se convierten en la expresión de la voluntad de los representantes, de los funcionarios y de los sectores concernidos respectivamente. Sus críticas y recelos a los principios y esquemas de la democracia representativa implican, respecto del interés general que es expresión de la voluntad general, la denuncia de que las instituciones políticas y administrativas de la democracia constitucional, que teóricamente se asientan en el principio de la voluntad general, en la práctica se convierten, a través de la representación libre, en criterio de los intereses particulares y en una fantasmagoría de intereses generales varios y aun divergentes. El loable intento de Glucksmann de salvar la incompatibilidad denunciada por el ginebrino es menos una operación de lógica que un ejercicio forzado; cuando sostiene que "la moderna idea del interés general es el fruto de la convergencia de dos corrientes tradicionales: el bien común de inspiración tomista y la idea ilustrada de la voluntad general"'13.

Más allá de estos apuntes conceptuales que subyacen tras las instituciones que analizamos, lo cierto es que la diferencia de perspectivas metodológicas se traduce, en último extremo, en una diferenciación funcional. Para la ciencia política -y en esto coincidimos con el profesor Nieto-, lo decisivo es determinar la función ideológica que juegan en el estado los intereses generales; mientras que, para el derecho constitucional y administrativo, lo importante - y en esto disentimos del ilustre académico- es el desenvolvimiento real de esa "objetividad respecto de los intereses generales" con que deben actuar las administraciones públicas, la interacción con esa realidad de los operadores del derecho en sus distintos niveles y la percepción común que, de todo ello, se genera en los ciudadanos.

\section{EL SIGNIFICADO GENERAL DEL ARTÍCULO 103.1 DE LA CONSTITUCIÓN}

La Constitución aborda de forma expresa el tema del servicio objetivo de las administraciones públicas a los intereses generales en su artículo 103.1, que reza: "La Administración Pública sirve con objetividad los intereses generales y actúa de acuerdo con los principios de eficacia, jerarquía, descentralización, desconcentración y coordinación con sometimiento pleno a la ley y al Derecho".

Sobre el mandato constitucional del "servicio objetivo... a los intereses generales", se asienta de forma radical la actuación de las administraciones públicas, de modo que otros principios podrán agregarse; pero este, en ningún caso, podrá obviarse y menos anularse. El legislador constituyente configura, por tanto, el interés general como un principio recogido en la Constitución. La consecuencia jurídica evidente es que las administraciones públicas, cuya actuación está sometida a la vinculación positiva a la norma (Winckler), disfrutan de un grado de autonomía de la voluntad que no 
es equivalente en este aspecto a la de un particular, sino que, en su actuación entre ellas y con los particulares, deberán ajustarse a la consecución del interés público que corresponda de forma objetiva o neutral, de conformidad con la voluntad general.

La objetividad es un principio constitucional de la actuación de las administraciones públicas establecida por el artículo 103.1 de la Constitución. Esta norma constitucional de que la administración sirve “con objetividad” los intereses generales ha de interpretarse como un mandato de neutralidad política e incluso de imparcialidad. Contiene una "habilitación general" para que la administración pueda intervenir cuando lo exijan los intereses generales y ahorma las condiciones de su ejercicio en forma de servicio objetivo. Entendido como la cualidad de adecuación a su objeto, a los fines que lo justifican, el principio de objetividad coincide con el de "buena administración", esto es, con la exigencia de una actuación administrativa bien fundada en el conocimiento de los hechos, en el derecho vigente y en los objetivos que se propone alcanzar. No obstante, ha de insistirse en que el principio de objetividad no excluye la legítima orientación política de la administración, sino solo la actuación partidista, contraria al principio de igualdad de los ciudadanos; la objetividad exige una buena administración, pero no una administración políticamente indiferente ${ }^{14}$.

El artículo 103.1 de la Constitución garantiza que las potestades administrativas reconocidas por el ordenamiento jurídico no se utilicen por las administraciones públicas para fines distintos de los que justificaron su creación y reconocimiento. El ordenamiento legal establece figuras y mecanismos con el fin de evitar las desviaciones de las administraciones respecto de lo que, en cada momento, y en función de las circunstancias, se considere interés general ${ }^{15}$. Concepto indeterminado que se fijará de acuerdo con la realidad social.

Como botón de muestra, se señalan tres ejemplos que derivan y penden del artículo 103.1 de la Constitución. Así, están las conductas penales tipificadas (como la prevaricación), en el artículo 63.1 de la Ley 30/1992, de 26 de noviembre, de régimen jurídico de las administraciones públicas y el procedimiento administrativo común (LRJPAC); los ilícitos administrativos (como la desviación de poder), en el artículo 70.1 de la Ley 29/1998, de 13 de julio, reguladora de la jurisdicción contenciosa-administrativa (LJ) o la exigencia de una organización electoral sobre la que recaiga la ejecución de las diferentes tareas materiales del proceso electoral y la responsabilidad de que todo se desarrolle con objetividad, respeto a los derechos fundamentales de los participantes en el proceso e igualdad de oportunidades (garantías del derecho de sufragio), en el artículo 8.1 de la Ley Orgánica 5/1985, de 19 de junio, del Régimen Electoral General(LOREG).

14 Cfr. Nieto, op. cit.; pp. $2226 \mathrm{s.}$

15 Cfr. García de Enterría, E.: “Una nota sobre el interés general como concepto jurídico indeterminado”, en Revista Española de Derecho Administrativo, n. ${ }^{\circ} 89$, enero-marzo 1996; pp. 68 s. También, Martín Retortillo, L. (ed.): De la jurisprudencia del Tribunal Constitucional, Institución Fernando el Católico, Zaragoza, 1985; pp. 391-428. Bermejo Vera, J.: “El “interés general” como parámetro de la jurisprudencia constitucional”, en Revista Vasca de Administración pública, n. ${ }^{\circ}$ 10, septiembre-diciembre 1984; pp. 103-136. 
La objetividad está relacionada de manera íntima con la neutralidad. Acaso no para la efectividad neutral predicada del aparato de justicia o de las administraciones públicas que se alcanza mediante una consideración del concepto como instrumento técnico, con idéntica objetividad y tecnicidad, con tal de que se haga el uso previsto por las normas; ni tampoco cuando se considera que sólo es alcanzable mediante su vinculación a una ley que posea a su vez un contenido obligatorio; pero sí cuando se reconoce que no es posible obtener un resultado si no se dota al sujeto que hipotéticamente debe producirlo de unas facultades o atributos que hagan posible su decisión.

La neutralidad es originariamente un concepto político, y como tal presupone la acción política y es resultado de ella. Como valor político, no cabe deducir el significado de la neutralidad de un pensamiento o una decisión ideal en el momento presente, sino que surge en lo colectivo, emana del grupo, que lo proyecta en una acción concreta, bajo la forma de una valoración o estimación de un comportamiento que determina como adecuado al valor neutralidad. De este modo, lo neutral se ha ligado a nociones diferentes en cada época, que siempre se relacionan con otro término relevante tanto de la configuración del estado como de su proyección administrativa: la expresión "intereses" (ya fueran éstos trascendentes o inmanentes, colectivos o generales, de acuerdo con las distintas primacías que han dominado en cada etapa de la historia). Ahora bien, dentro del proceso de juridificación de todos los contenidos políticos — seguido sin duda con el afán de reducir al mínimo los espacios de arbitrariedad a los representantes del poder y a los agentes de las potestades públicas-, la neutralidad encuentra su equivalente más próximo en los conceptos de objetividade imparcialidad, propios de la Administración contemporánea ${ }^{16}$.

En el caso de España, la correcta interpretación del concepto neutralidad y el de su inmediato la imparcialidad ha de extraerse de la construcción que se ha hecho a partir de lo dispuesto en el artículo 103.1 de la Constitución sobre la actividad de la administración en relación con los intereses generales. Este precepto impone de forma expresa a las administraciones públicas que sirvan al interés público, pero han de hacerlo con "objetividad" y con "sometimiento pleno a la ley y al derecho". Estos dos límites - junto con otros que no explicita el precepto constitucional, pero que están

16 Conceptos que se recogen, por ejemplo, en la STC 197/1988 respecto de las juntas electorales a propósito de la discusión sobre su naturaleza jurídica: “No se puede negar razón al Ministerio Fiscal cuando sostiene que las Juntas Electorales presentan, en su composición y funciones, notables peculiaridades que las apartan del régimen general de las Administraciones Públicas. Sin pretender una exposición exhaustiva de las mismas, es cierto que la composición de las Juntas está fuertemente judicializada y que todos sus miembros son inamovibles durante los períodos para los que son elegidos, sin que guarden relación alguna de dependencia con la Administración y que, en su funcionamiento, están protegidos por una serie de garantías tendentes a asegurar su imparcialidad y objetividad en el cumplimiento de la misión que la Ley les encomienda de asegurar la transparencia y objetividad del proceso electoral y del principio de igualdad...; [pero] tales no autorizan a atribuirles la condición de órganos jurisdiccionales, ni a desconocer que son órganos administrativos que realizan una actividad de tal naturaleza, pues así lo evidencia el contenido del capítulo III, título I LOREG, encabezado por la rúbrica de Administración Electoral, lo da por supuesto la STC 154/1988, de 21 de julio, y es doctrina pacífica unánimemente aceptada". 
intrínsecamente unidos a ellos - garantizan la interdicción de toda actividad que se desentienda de los medios. Se deduce sin mayores dificultades que esa objetividad con la que deben proceder las administraciones públicas excluye cualquier clase de discriminación o de decisión únicamente subjetiva ${ }^{17}$. La ley y el derecho son los marcos que la Constitución fija para que, con total sumisión a ellos, las administraciones públicas laboren por el interés general con garantía de imparcialidad ante los ciudadanos y las demás administraciones.

Siguiendo con esta cuestión, Sáinz ha escrito que "el principio de imparcialidad afecta directamente a las autoridades y al personal de las Administraciones Públicas (...), aunque su objetivo [es] la neutralidad de la Administración frente a los intereses particulares. La imparcialidad no se opone a la acción política global de la Administración, sino a la decisión singular determinada por la influencia de un interés particular o tomada por quien puede parecer que actúa motivado por ese interés”18.

Por supuesto, sería una ingenuidad desconocer que el interés general al que alude el artículo 103.1 de la Constitución debe conformarse con cada una de las administraciones públicas existentes en España y más cuando nuestro estado es compuesto, si no complejo. Esto provoca a veces conflictos de intereses públicos. No es extraordinario que dos o más administraciones no necesariamente antagonistas de partida, como consecuencia de sus actividades de servicio de los intereses públicos que les corresponden dentro de su ámbito competencial, adopten medidas contradictorias o que entran en conflicto.

Se infiere también con toda certeza del inciso del artículo 103.1 de la Constitución que estamos tratando la obligación de buscar el interés público prevalente que siempre se verificará en cualquier situación. Esto es, que habrá que encontrar, en caso de conflicto con otras administraciones públicas, una salida que no dañe el interés general, que puede estar, claro es, sostenido por distintas administraciones y no solo por la Administración General del Estado. Las administraciones públicas deben garantizar la participación y ser verdaderas representantes del interés general, mediante la promoción de cauces continuos de encuentro y diálogo en pos de ese bien común, junto con un adecuado ejercicio crítico de la racionalidad, que huya de dogmatismos y apriorismos.

Diremos por último respecto del interés general o, si se prefiere, de los intereses generales, que, como ya reconocía Nieto, es "imposible realizar una enumera-

17 No es extraño encontrarse en la práctica (García Trevijano y Moret) con posturas administrativas consistentes en considerar que, por ejemplo, cualquier ahorro en el gasto público (incluso no accediendo al pago de cantidades ciertamente debidas a un administrado) es conforme al interés público, con el argumento de que ello permitirá utilizar el dinero ahorrado (en detrimento de un derecho de un particular) en beneficio de la comunidad. Obviamente, esta forma de entender el interés público nada tiene que ver con lo que el artículo 103.1 de la Constitución pretende garantizar. Y ello precisamente enlaza con los medios (y límites) que podrá utilizar la Administración para alcanzar el interés público (rectamente entendido).

18 Sainz, F.: Voz imparcialidad, en “Enciclopedia Jurídica Básica”, II, Civitas. Madrid, 1995; p. 3374. 
ción exhaustiva de los tipos normativos que aparecen en las leyes, dado el número de estas". Mucho más productivo y eficaz es la sistematización de sus variantes. Reproducimos la de Häberle ${ }^{19}$, a la que sigue por entero Nieto ${ }^{20} y$, en parte, Sainz ${ }^{21}$. Según el autor alemán, los tipos legales más corrientes pueden agruparse en las siguientes figuras:

a) Apoderamiento para delegar y objeto de la delegación (salus publica per delegationem o delegatio salutis publicae causa). La ley autoriza a las administraciones públicas para que, mediando un interés general, actúe o no actúe.

b) Apoderamiento al juez para que realice determinadas actuaciones procesales, por ejemplo, suspensión de efectos de un acto administrativo (ex proceso salus publica).

c) Legitimación de actuaciones administrativas en supuestos de urgencia o necesidad (actio pro salute publica).

d) Legitimación de actuaciones administrativas de prohibición, control o imposición de deberes (salus publica ex negatione libertatis).

e) Legitimación de actuaciones administrativas para actos ampliatorios de la esfera jurídica de los particulares (salus publica ex extensione libertatis).

f) Legitimación de actuaciones administrativas de adaptación a necesidades nuevas (reformatio ex salute publica).

g) Legitimación de actuaciones administrativas de excepción de regímenes generales (exceptio, exemptio, inmunitas salutis publicae causa).

h) Imposición de un deber de reserva o, por el contrario, de publicidad.

En este punto, debe hacerse una mención a los principios (derivados) de proporcionalidad y adopción de la medida menos restrictiva para el individuo (principio de menor onerosidad). Si fuese necesario adoptar, siempre por razones de interés público, medidas restrictivas sobre los derechos fundamentales, la decisión debe atender a los dos principios citados. Se trata de auténticos principios generales del derecho, al margen de que el derecho positivo los haya recogido en algunas materias. Como sucede, por ejemplo, en la ejecución de los actos administrativos, según el artículo 96 de la LRJPAC.

19 Cfr. Häberle, P.: Öffentliches Interesse als juristisches Problem, Berliner Wissenschafts, Berlín, 1970; pp. 39-193.

20 Cfr. Nieto, op. cit.; pp. 2216 s.

21 Cfr. Sainz, F.: Conceptos jurídicos indeterminados, interpretación y discrecionalidad administrati-

52 va, Civitas, Madrid, 1976; pp. 318-321. 
La sentencia del Tribunal Constitucional 14/2003, de 28 de enero, entre otras muchas -anotan García Trevijano y Moret en la sinopsis del precepto que ofrecen en la página web del Congreso de los Diputados-, "afrontó el conflicto entre un interés general o público, al que por definición ha de servir la Administración, y derechos fundamentales de los ciudadanos. Señaló la sentencia que las limitaciones que se establezcan no pueden obstruir el derecho fundamental más allá de lo razonable, de donde se desprende que todo acto o resolución que limite derechos fundamentales ha de asegurar que las medidas limitadoras sean necesarias para conseguir el fin perseguido, haciendo hincapié el Alto Tribunal en la necesidad de que la medida restrictiva de un derecho fundamental supere "el juicio de proporcionalidad" a cuyo efecto es necesario constatar si se cumplen los tres requisitos o condiciones siguientes: (i) si la medida es susceptible de conseguir el objetivo propuesto (juicio de idoneidad); (ii) si, además, es necesaria, en el sentido de que no exista otra medida más moderada para la consecución de tal propósito (juicio de necesidad); (iii) y, finalmente, si la misma es ponderada o equilibrada, por derivarse de ella más beneficios o ventajas para el interés general que perjuicios sobre otros bienes o valores en conflicto".

Por otra parte, el sometimiento pleno a la ley y al derecho recogido en el artículo 103.1 de la Constitución se conecta con el artículo 106.1 del mismo cuerpo normativo. Este último precepto atribuye a los órganos jurisdiccionales competentes el control de la potestad reglamentaria y la legalidad de la actuación administrativa, y el sometimiento de esta a los fines que la justifican. Como ha señalado en numerosas sentencias el Tribunal Constitucional, los artículos 103.1 y 106.1 de la Constitución impiden que puedan existir comportamientos (por acción u omisión) de las administraciones públicas que queden al margen del control judicial ordinario.

\section{CONCLUSIONES}

El escenario de los países democráticos de nuestro entorno revela (Martín ${ }^{22}$ ) la demanda de unas administraciones públicas democráticas y participativas, con valores políticos, relacionales, orientadas a la complejidad y diversidad de fuerzas o grupos de interés que se desenvuelven en el seno de la sociedad; equilibradas; competitivas; colaborativas con otras organizaciones públicas y privadas; adaptadas a las necesidades de la sociedad, al entorno en general; flexibles, anticipadoras; inteligentes, pensantes, innovadoras y flexibles; eficaces, eficientes y de calidad, que orienten y aproximen las decisiones políticas y su propia actividad a los ciudadanos. Unas administraciones públicas que tengan el valor y la capacidad de dar respuesta, corregir sus errores, aprender de la experiencia y que sean sensibles a las fuerzas que actúan, tanto en su entorno como internamente; así como de desarrollar y consolidar estructuras y esquemas de comprensión y de acción en su orientación continua hacia la consecución de su visión, misión, objetivos y metas con el único origen en el interés

22 Cfr. Martín, J.I.: “Valor y valores de una administración al servicio público”, en Auditoría Pública, n. ${ }^{\circ} 38$ (2006); pp. 25-34. 
general desde una posición servicial de objetividad. Pues, no se olvide, según el artículo 103.1 de la Constitución, “la Administración pública sirve con objetividad los intereses generales".

Como correlato de lo anterior, la idea de servicio de los intereses generales debe presidir también la actuación de quien quiera que realice una función pública. Autoridad o funcionario, político o empleado debe hacer siempre lo que sea mejor para los intereses generales. Lo que constituye un mandato para todos y cada uno de los que desempeñan una actividad administrativa. Por eso, los programas de actuación de las administraciones públicas deben elaborarse sobre la idea de servicio, tratando de imbuir la idea de que el funcionario está al servicio de la colectividad ${ }^{23}$ y teniendo muy presentes los "conflictos - y las medidas para prevenirlos y darles una solución adecuada-"; puesto que, además, "constituyen uno de los temas centrales de los congresos sobre ética pública"24, materia imprescindible para avanzar en unas administraciones públicas que de veras sirvan con objetividad los intereses generales y ayuden a la sociedad a librarse de la lacra de la corrupción.

Dicho escenario exige ciertamente una diferente concepción de la organización pública, lo que escapa de las pretensiones de esta colaboración. Esbozaremos, no obstante, algunas ideas sobre este punto ${ }^{25}$. Sus funciones, estructura y cultura, la dirección estratégica y gestión, la financiación, la gestión del capital humano y del conocimiento, los procesos de prestación de servicios al ciudadano y de relación con el entorno, las tecnologías y los sistemas deben ser también objeto de ese mejoramiento orgánico de las administraciones públicas en su tarea de servicio. Sobre todo, porque se trata de una realidad para la que no están del todo preparadas y requiere de unos líderes públicos altamente cualificados, que destaquen por su capacidad técnica (en la gestión pública y en el ámbito sectorial de actuación), sus valores humanos y su especial concienciación e implicación por el servicio público, su capacidad para escuchar, dialogar, consensuar y conciliar los diferentes intereses de las distintas administraciones y, en fin, para perseguir ese interés general que la Constitución marca para las administraciones públicas.

El aspecto del liderazgo (tanto político como directivo) es fundamental en las administraciones públicas de una democracia constitucional $\left(\right.$ Pfeffer $\left.^{26}\right)$. Es posible

23 Cfr. Rodríguez-Arana, J.: Sobre la enseñanza de la ética pública, Papeles de Trabajo del Instituto Universitario Ortega y Gasset (Serie Gobierno y Administración Pública), Madrid, 1995.

24 González Pérez, J.: Ética en la administración pública, Real Academia de Ciencias Morales y Políticas, Madrid, sesión de 20 de febrero de 1995; p. 128.

25 Vid., entre otros, López Camps, J., y Gadea. A.: “Una nueva Administración pública. Estrategias y métodos para mejorar la calidad y la eficiencia del e-Gobierno”, en IVAP (Instituto Vasco de Administración Pública), Bilbao, 2001; Ramió, C.: Teoría de la organización y Administración pública, Tecnos/UPF, Madrid, 1999; OCDE: La Administración al servicio público, Ministerio para las Administraciones Públicas, Madrid, 1996; Mendoza, X.: Management público e indicadores de gestión: una perspectiva organizativa, ESADE,

$54 \quad$ Barcelona, 1993. 
que, como ya apuntaba Kooiman ${ }^{27}$, haya de construirse un sistema de codirección entre la sociedad civil y las administraciones públicas para dar solución a los problemas comunes o de interés general. La consecuencia es que las administraciones deberán escoger continuamente medios y fines al mismo tiempo, afrontar el futuro con valor y diferenciarse por sus valores al servicio de los ciudadanos y de la sociedad democrática del estado constitucional.

\section{BIBLIOGRAFÍA}

Baena del Alcázar, M.: "Los principios reguladores y la estructura de la Administración: artículo 103.1 y 2.", en Comentarios a la Constitución española de 1978, dirigidos por Óscar Alzaga Villaamil, Vol. VIII (p. [381]-409), Cortes Generales, Madrid, 1996-1999.

Barcelona, J.: "Principio de legalidad y organización administrativa (gobierno, administración y reserva de ley en el artículo 103.2 de la Constitución)", en Estudios sobre la Constitución española: homenaje al Profesor Eduardo García de Enterría, coordinados por Sebastián Martín Retortillo, Vol. III (p. 2357-2452), Civitas, Madrid, 1991.

Bermejo Vera, J.: “El "interés general” como parámetro de la jurisprudencia constitucional”, en Revista Vasca de Administración pública, n. ${ }^{\circ}$ 10, septiembre-diciembre 1984.

Canales, J. M.: “La organización y la función pública: artículo 103.3. “", en Comentarios a la Constitución española de 1978, dirigidos por Óscar Alzaga Villaamil, Vol. VIII, (p. [411]-424), Madrid, Cortes Generales, 1996-1999.

Friedrich, C. J.: El hombre y el gobierno (una teoría empírica de la política), Tecnos, Madrid, 1968.

- El interés público, Roble, México DF, 1967.

García de Enterría, E.: “La Constitución como norma jurídica”, en A. Predieri y E. García de Enterría (dirs.) y otros, La Constitución española de 1978. Estudio sistemático, Madrid, 1981.

- La lengua de los derechos. La formación del Derecho Público europeo tras la Revolución Francesa. Alianza Universidad. Madrid, 1995.

- "Una nota sobre el interés general como concepto jurídico indeterminado", en Revista Española de Derecho Administrativo, n. ${ }^{\circ}$ 89, enero-marzo 1996.

García de Enterria, E., y Fernández, T.-R.: Curso de Derecho Administrativo, I. Civitas, Madrid, 1996.

Glucksmaan, A.: Les Maîtres Penseurs, Grasset, París, 1977.

González Pérez, J.: Ética en la administración pública, Real Academia de Ciencias Morales y Políticas, Madrid, sesión de 20 de febrero de 1995.

Häberle, P.: Öffentliches Interesse als juristisches Problem, Berliner Wissenschafts, Berlín, 1970.

Kelsen, H.: Esencia y valor de la democracia, Labor, Barcelona, 1977.

27 Cfr. Kooiman, J.: Modern Governance, Sage, Londres, 1993. 
Kooiman, J.: Modern Governance, Sage, Londres, 1993.

López Camps, J., y Gadea. A.: “Una nueva Administración pública. Estrategias y métodos para mejorar la calidad y la eficiencia del e-Gobierno", en IVAP (Instituto Vasco de Administración Pública), Bilbao, 2001.

Martín, J.I.: "Valor y valores de una administración al servicio público", en Auditoría Pública, n. ${ }^{\circ} 38$ (2006).

Martín Retortillo, L. (ed.): De la jurisprudencia del Tribunal Constitucional, Institución Fernando el Católico, Zaragoza, 1985.

Mendoza, X.: Management público e indicadores de gestión: una perspectiva organizativa, ESADE, Barcelona, 1993.

Nieto, A.: "La Administración sirve con objetividad los intereses generales", en Estudios sobre la Constitución española: homenaje al Profesor Eduardo García de Enterría, coordinados por Sebastián Martín Retortillo, Vol. III (p. 2185-2253), Civitas, Madrid, 1991.

OCDE: La Administración al servicio público, Ministerio para las Administraciones Públicas, Madrid, 1996.

De Otto, I.: Derecho Constitucional. Sistema de fuentes, Madrid, 1987.

Pfeffer, J.: Managing with Power, Harvard University Press, Boston, 1992.

Pérez Royo, J.: Las fuentes del Derecho, Madrid, 1988.

- Curso de Derecho Constitucional, Madrid, 1996.

Pulido, M.: El acceso a los cargos y funciones públicas: un estudio del artículo 23.2 de la Constitución; Civitas, Madrid, 1992.

Ramió, C.: Teoría de la organización y Administración pública, Tecnos/UPF, Madrid, 1999.

Rodríguez-ARANA, J.: Sobre la enseñanza de la ética pública, Papeles de Trabajo del Instituto Universitario Ortega y Gasset (Serie Gobierno y Administración Pública), Madrid, 1995.

Sainz, F.: Conceptos jurídicos indeterminados, interpretación y discrecionalidad administrativa, Civitas, Madrid, 1976.

— Voz imparcialidad, en “Enciclopedia Jurídica Básica”, II, Civitas. Madrid, 1995.

Sánchez Morón, M.: Derecho de la función pública, Tecnos, Madrid, 1996.

Sartori, G.: Elementos de teoría política, Alianza Editorial, Madrid, 1999.

Schmitt, C.: El concepto de lo político. Alianza Editorial, Madrid, 1998.

De Vega, P.: “El problema de los derechos fundamentales en el Estado Social”, en Anuario Jurídico de La Rioja. Diputación General de La Rioja-Universidad de La Rioja. Logroño, 1997.

- Legitimidad y representación en la crisis de la democracia actual, WP núm. 141. Institut de Ciències Polítiques y Socials. Barcelona, 1998.

- "Supuestos políticos y criterios jurídicos en la defensa de la Constitución: algunas peculiaridades del ordenamiento constitucional español", en Revista de Política Comparada, n. ${ }^{\circ}$ 10-11 (1984).

VV. AA.: Administración y Constitución: el principio de cooperación, en Documentación Administrativa, N. ${ }^{\circ} 240$ monográfico (oct.-dic. 1994).

- El Gobierno y la Administración, en Documentación Administrativa, N. ${ }^{\circ}$ 246-247 monográfico (sept. 1996-abr. 1997).

56 Weber, M.: Economía y sociedad, Fondo de Cultura Económica, México DF, 1944. 
EL PRINCIPIO DE SERVICIO OBJETIVO A LOS INTERESES GENERALES EN LA CONSTITUCIÓN Y SU TRADUCCIÓN LEGISLATIVA 